\title{
ESTRATÉGIAS PARA REDUÇÃO DO PORTE DE GIRASSOL ORNAMENTAL PARA COMERCIALIZAÇÃO EM VASO $\left({ }^{1}\right)$
}

\author{
CAROLINE DE MOURA D’ANDRÉA MATEUS $\left({ }^{2}\right)$; JÚLIO CESAR BOGIANI $\left({ }^{2}\right)$; ALEXSANDER SELEGUINI $\left({ }^{3}\right)$; \\ REGINA MARIA MONTEIRO DE CASTILHO $\left({ }^{4}\right)$; MAX JOSÉ DE ARAÚJO FARIA JUNIOR $\left({ }^{*}\right)$
}

\begin{abstract}
RESUMO
O objetivo do trabalho foi avaliar o uso de tela plástica fotosseletiva e de doses do regulador de crescimento paclobutrazol $\left(0 ; 0,25 ; 0,50 ; 0,75\right.$ e $1,0 \mathrm{mg} \mathrm{L}^{-1}$ de substrato) no desenvolvimento de plantas de girassol ornamental cv. Sunbright Supreme em ambiente protegido, visando à comercialização em vasos. Dois abrigos foram cobertos com filme de polietileno transparente de 0,1 $\mathrm{mm}$ de espessura e, em um deles, o filme plástico foi aplicado sobre tela plástica de cor azul, com 30\% de sombreamento. Foram realizadas avaliações de microclima e fitotécnicas. A radiação solar global foi reduzida em $27,5 \%$ com o uso da tela fotosseletiva, porém, houve pouca influência sobre a temperatura e umidade relativa do ar. Ainda, o uso de tela fotosseletiva não reduziu o porte das plantas e não influenciou significativamente o diâmetro do capítulo, o número de folhas por planta e o tempo para a floração. Todavia, o uso de paclobutrazol reduziu significativamente a altura das plantas, de modo que permitisse sua comercialização em vasos, sem prejuízos ao seu aspecto visual, visto que não diminuiu o diâmetro do capítulo. O uso do regulador de crescimento retardou a floração, por um tempo que variou com a dose empregada, mas que não ultrapassou uma semana.
\end{abstract}

Palavras-chave: tela fotosseletiva, regulador de crescimento, Helianthus annuus, cultivo protegido.

\section{ABSTRACT \\ STRATEGIES FOR REDUCING THE HEIGHT OF POTTED ORNAMENTAL SUNFLOWER PLANTS}

The objective of the research was to evaluate the use of photoselective plastic shadenet and the effect of plant growth retardant paclobutrazol drench at different concentrations $(0 ; 0.25 ; 0.50 ; 0.75$ e 1.0 $\mathrm{mg} \mathrm{L}^{-1}$ of substrate) on potted plants of sunflower cv Sunbright Supreme grown under protected environment. Two greenhouses were covered with transparent polyethylene film, 0,1 mm thick, and at one of them, the plastic film was applied over a blue photoselective plastic shadenet ( $30 \%$ of shading). Microclimatic and agronomic parameters were evaluated. The solar radiation was reduced by $27.5 \%$ when the shadenet was used, which resulted in a very low influence on the air temperature and humidity in the shelter. Further, the use of the shadenet did not reduced plant height and did not influenced inflorescence diameter, the number of leaves per plant and the interval from transplant to flowering. Nevertheless, paclobutrazol substrate drench decreased plant height, leading to more compact plants that can be grown and commercialized in pots, without any loss to plant quality, since the inflorescence diameter was not affected. The use of the growth retardant delayed the flowering according to the drench concentration, but not exceeding one week.

Key words: photoselective plastic shadenet, plant growth retardant, Helianthus annuus, greenhouse.

( $\left.{ }^{1}\right)$ Recebido para publicação em 20 de maio de 2008 e aceito em 17 de abril de 2009.

$\left({ }^{2}\right)$ Programa de Pós-Graduação em Agronomia da UNESP/Câmpus de Botucatu (Doutorado).

$\left({ }^{3}\right)$ Setor de Horticultura, Escola de Agronomia e Engenharia de Alimentos, Universidade Federal de Goiás.

$\left({ }^{4}\right)$ Departamento de Fitotecnia, Tecnologia de Alimentos e Sócio-Economia, UNESP/Câmpus de Ilha Solteira.

$\left({ }^{5}\right)$ Departamento de Apoio, Produção e Saúde Animal, UNESP/Campus de Araçatuba, Rua Clóvis Pestana 793, 16050-680 Araçatuba (SP). E-mail: maxfaria@fmva.unesp.br ${ }^{*}$ ) Autor correspondente. 


\section{INTRODUÇÃO}

As exportações brasileiras de flores corresponderam a US\$29,6 milhões, em 2006, com crescimento de mais de $124 \%$ entre 2001 e 2006, indicando expansão maior que de outros produtos agrícolas da pauta nacional de exportações. Neste cenário, destacou-se o Estado de São Paulo como maior produtor e exportador (JUNQUEIRA e PEETZ, 2007). Das plantas ornamentais atualmente produzidas no Brasil, o girassol vem ganhando grande expressão no mercado, porém, os híbridos ornamentais disponíveis não se diferenciam muito das cultivares de girassol granífero em relação ao porte (NEves, 2003). Tal condição causa perda do valor comercial para o cultivo em vaso, tornando necessária a utilização de medidas que viabilizem a obtenção de um padrão estético aceitável, ou seja, plantas mais compactas.

Dentre as possibilidades, existe a produção do girassol ornamental em cultivo protegido, utilizandose materiais de cobertura fotosseletivos capazes de promover alteração no espectro de radiação que alcança as plantas. A qualidade da luz desempenha um importante papel na fotobiologia, com efeitos na fenologia, qualidade e produção das culturas, promovendo respostas específicas que podem se constituir em ferramenta interessante na manipulação da arquitetura das plantas, com possibilidade de redução do porte (RAJAPAKSE e KELLY, 1992, RAJAPAKSE et al., 1999, Wilson e RajapaKse, 2001, Cuquel et al., 2003).

Outro recurso, que já tem aplicação em várias espécies ornamentais, é o uso de reguladores de crescimento, como o paclobutrazol (PBZ), composto sintético do grupo dos triazóis que inibe a biossíntese de ácido giberélico (Fletcher et al., 2000). O paclobutrazol foi eficaz no controle da altura de plantas de girassol, como estudado por Almeida e Pereira (1996) e Vernieri et al. (2003), principalmente, quando aplicado no solo ou substrato. O produto é absorvido pelas raízes, com maior translocação do que quando aplicado nas folhas. Além da redução do porte das plantas, WhipKer e DAsoju (1998), porém, observaram efeitos adversos com o uso do regulador de crescimento, como a redução do diâmetro da haste e o atraso na floração, enquanto WANDERLEY et al. (2007) verificaram reduções significativas no tamanho do capítulo com doses mais elevadas de paclobutrazol, o que é esteticamente indesejável.

Portanto, a definição do material de cobertura apropriado para o controle da altura de plantas de girassol ornamental, bem como da dose adequada de paclobutrazol para obtenção de plantas compactas, sem prejuízo à qualidade das inflorescências, devem ser tema de estudos criteriosos, a fim de que se possa contar com indicações precisas aos produtores. $\mathrm{O}$ objetivo do presente trabalho foi avaliar os efeitos do uso de tela plástica fotosseletiva e de diferentes doses de paclobutrazol, bem como de suas interações, sobre o desenvolvimento de plantas de girassol ornamental cv. Sunbright Supreme em ambiente protegido, visando à sua comercialização em vasos.

\section{MATERIAL E MÉTODOS}

O experimento foi desenvolvido de $14 / 10$ a $13 / 12 / 2004$, no município de Ilha Solteira a $20^{\circ} 22^{\prime}$ S; $51^{\circ} 22^{\prime} \mathrm{W}$ e altitude de $330 \mathrm{~m}$.

Plantas envasadas de girassol (Helianthus annuus) ornamental cv. Sunbright Supreme foram submetidas a aplicações de doses crescentes de paclobutrazol $\left(0 ; 0,25 ; 0,50 ; 0,75\right.$ e $1,00 \mathrm{mg} \mathrm{L}^{-1}$ de substrato), em dois ensaios simultâneos, em ambiente protegido sem e com tela plástica fotosseletiva.

Os dois abrigos para cultivo protegido tinham orientação Leste-Oeste, dimensões de 5,2 x 15,0 m, pé direito de eucalipto com $2,8 \mathrm{~m}$ de altura e teto em forma de arco coberto com filme de polietileno transparente de $0,1 \mathrm{~mm}$ de espessura. Um deles recebeu, sob o filme de polietileno, a aplicação adicional de tela plástica fotosseletiva azul, com $30 \%$ de sombreamento, sendo o mesmo material utilizado no fechamento lateral. $\mathrm{O}$ abrigo para cultivo protegido, que não recebeu a aplicação de tela fotosseletiva, teve seu perímetro fechado com tela de polipropileno preta, com $50 \%$ de sombreamento, até $1,5 \mathrm{~m}$ de altura.

Segundo o fabricante, a tela fotosseletiva azul é capaz de alterar o espectro da luz, reduzindo as ondas no comprimento do vermelho e do vermelhodistante, aumentando as ondas no comprimento do azul, de modo que as plantas cultivadas sob sua proteção se desenvolvam mais lentamente, obtendose plantas compactas e com folhagem verde-escura, podendo ocorrer atraso na floração (POLYSACK, 2007).

A semeadura ocorreu em 14/10/2004, em bandejas de poliestireno expandido, e, em 25/10/ 2004 , as mudas foram transplantadas para vasos com substrato comercial, com capacidade de 1,2 L, colocando-se uma planta por recipiente.

Três aplicações de paclobutrazol foram feitas no substrato, antes da emissão do botão floral, em 25/ $10,10 / 11$ e $25 / 11 / 04$, cada uma delas observandose as doses estabelecidas em cada tratamento.

A adubação consistiu na aplicação de 3,6 $\mathrm{g}$ do fertilizante de liberação lenta Basacote ${ }^{\circledR} 3 \mathrm{M}$ (fórmula 15-9-12) por recipiente. As plantas foram 
irrigadas por um sistema de gotejamento, com um emissor por vaso, fornecendo cerca de $0,9 \mathrm{~L} \mathrm{dia}^{-1} \mathrm{de}$ água. Quando necessário, procedeu-se ao tratamento fitossanitário adequado ao bom desenvolvimento das plantas, visando, principalmente, ao controle de mosca-branca (Bemisia tabaci) e de lagartas.

As avaliações micrometeorológicas foram realizadas no período de $25 / 10$ a 13/12/2004, com determinações da radiação solar global, da temperatura do ar e da umidade relativa do ar, em cada ambiente protegido e em campo aberto. Piranômetros de fotodiodo de silício (SP Lite, da SciTec Instruments, e Licor LI-200X) e sensores de temperatura e umidade relativa do ar (Vaisala HMP45C) foram acoplados a sistemas de aquisição de dados (CR10X e CR23X, da Campbell Scientific).

As avaliações fitotécnicas consistiram na anotação da altura de plantas (após 44 dias do transplantio), medida do colo da planta até seu ápice (planta mantida ereta); da taxa de crescimento absoluto das plantas, referente ao período de 44 dias a partir transplantio, conforme BENINCASA (1988); do número de folhas por planta aos 44 dias após o transplantio; do diâmetro do receptáculo floral (ou disco) quando os capítulos estavam completamente formados; do diâmetro do capítulo floral (receptáculo floral e flores liguladas da periferia) quando as inflorescências também estavam completamente formadas, e do tempo, após a semeadura, para a floração (considerando-se $50 \%$ de capítulos formados).

Os dois ensaios foram estabelecidos no delineamento em blocos ao acaso, com cinco tratamentos (doses de paclobutrazol), quatro repetições e 12 plantas por parcela. Os resultados foram submetidos à análise de variância para grupo de experimentos (ZimmermanN, 2004; BAnZATto e KRONKA, 2006), modelo fixo. A análise conjunta dos dois ensaios permitiu que fossem detectados os efeitos das doses de paclobutrazol, dos ambientes (uso da tela fotosseletiva) e da interação entre ambos sobre o desenvolvimento das plantas de girassol.

\section{RESULTADOS E DISCUSSÃO}

O uso da tela plástica sob o filme de polietileno reduziu a disponibilidade de radiação de 16,7 para $12,1 \mathrm{MJ} \mathrm{m}^{-2} \mathrm{dia}^{-1}$ (Tabela 1), o que correspondeu a uma atenuação média de $27,5 \%$, bastante próxima à especificada comercialmente. O sombreamento total, causado pelo filme de polietileno e pela tela fotosseletiva, foi de 47,4\% quando considerada a radiação solar global em campo aberto. A energia radiante mínima (limite trófico) para que a maioria das plantas possa produzir assimilados para sua mantença é de 8,4 $\mathrm{MJ} \mathrm{m}^{-2}$ dia $^{-1}$ (MARTins et al., 1999), o que foi superado nos dois ambientes protegidos (com e sem uso de tela fotosseletiva), considerando-se as médias do período compreendido entre $25 / 10$ e 13 / 12/2004 (Tabela 1).

As temperaturas mínimas do ar foram muito próximas entre os ambientes estudados e o campo aberto (Tabela 1). A baixa capacidade de retenção de energia pelos abrigos, durante a noite, resulta da elevada transparência das coberturas de polietileno às radiações de ondas longas (PAPADAKIS et al., 2000, CASTILla, 2005), além das perdas por convecção através das telas plásticas utilizadas no fechamento lateral, que não impedem as trocas de ar.

Tabela 1. Valores médios da radiação solar global (totais diários), das temperaturas mínimas, médias e máximas diárias do ar, e das umidades relativas mínimas, médias e máximas diárias do ar, em ambiente protegido com e sem aplicação de tela fotosseletiva sob o filme plástico e em campo aberto

\begin{tabular}{lccc}
\hline Variáveis ambientais & \multicolumn{2}{c}{ Ambiente Protegido } & Campo aberto \\
\cline { 2 - 3 } $\begin{array}{lccc}\text { Radiação solar global } \\
\left(\text { MJ m }^{-2} \text { dia }^{-1}\right)\end{array}$ & 12,1 & 16,7 & 23,0 \\
Temperatura do ar $\left({ }^{\circ} \mathrm{C}\right)$ & & & 20,8 \\
Mínima & 20,4 & 20,4 & 25,6 \\
Média & 25,7 & 25,7 & 31,3 \\
Máxima & 32,3 & 32,8 & 43,4 \\
Umidade relativa do ar $(\%)$ & & & 68,1 \\
Mínima & 40,3 & 38,9 & 88,3 \\
Média & 65,9 & 65,3 & 86,2 \\
Máxima & 86,3 & & \\
\hline
\end{tabular}


O emprego da tela fotosseletiva, apesar da grande atenuação da radiação solar, não contribuiu para a redução das temperaturas máximas no cultivo protegido (Tabela 1). As boas condições de ventilação dos abrigos minimizaram os efeitos do sombreamento sobre a temperatura interna, como discutido por Montero e Antón (1994) e Mantallana e Montero (2001).

A temperatura do ar, nos dois ambientes protegidos, variou entre $16^{\circ} \mathrm{C}$ e $38^{\circ} \mathrm{C}$, embora a maior parte do período tenha se situado abaixo de $34{ }^{\circ} \mathrm{C}$, com temperaturas médias em torno de $26^{\circ} \mathrm{C}$ (Tabela $1)$, muito próximas das ideais para a cultura do girassol (CASTRO et al., 1997). Também, para a umidade relativa (mínima, média e máxima) do ar, foram observadas pequenas variações entre os ambientes (Tabela 1), certamente, como conseqüência das pequenas diferenças de temperatura entre eles e das boas condições de ventilação no cultivo protegido.

Serrano Cermeño (1994) e Hanan (1998) alertam que umidades elevadas em ambiente protegido, como as observadas no período do ensaio, podem causar efeitos indesejáveis como a condensação de água na face interna do filme plástico da cobertura, nos horários de temperaturas mais baixas, com redução da transmitância da radiação solar, além de favorecer o surgimento e desenvolvimento de doenças criptogâmicas nas plantas.

No que diz respeito às características fitotécnicas, não foram detectadas interações significativas entre o uso da tela fotosseletiva e as doses de paclobutrazol estudadas. O uso de tela fotosseletiva não reduziu significativamente a altura das plantas (Tabela 2), após 44 dias do transplantio, resultados distintos daqueles indicados por CUQUeL et al. (2003) com outras espécies de plantas ornamentais.

BLISKA JUNIOR e HONÓRIO (1994) constataram que o filme de polietileno promove incremento relativo nos comprimentos de onda na faixa do vermelhodistante, cujo efeito é antagônico ao proporcionado pela tela fotosseletiva, o que pode explicar os resultados conseguidos, uma vez que a tela estava aplicada sob o filme plástico. Há de se considerar, ainda, que cada espécie representa um padrão de resposta específico à manipulação do espectro solar, notadamente, à redução de radiação nos comprimentos de onda na faixa do vermelho-distante (WILSON e RAJAPAKSE, 2001). Nas plantas de girassol verificaramse 18 folhas, aproximadamente, em ambos os ambientes de cultivo, não se constatando efeito do uso de tela fotosseletiva sob o filme plástico (Tabela 2).

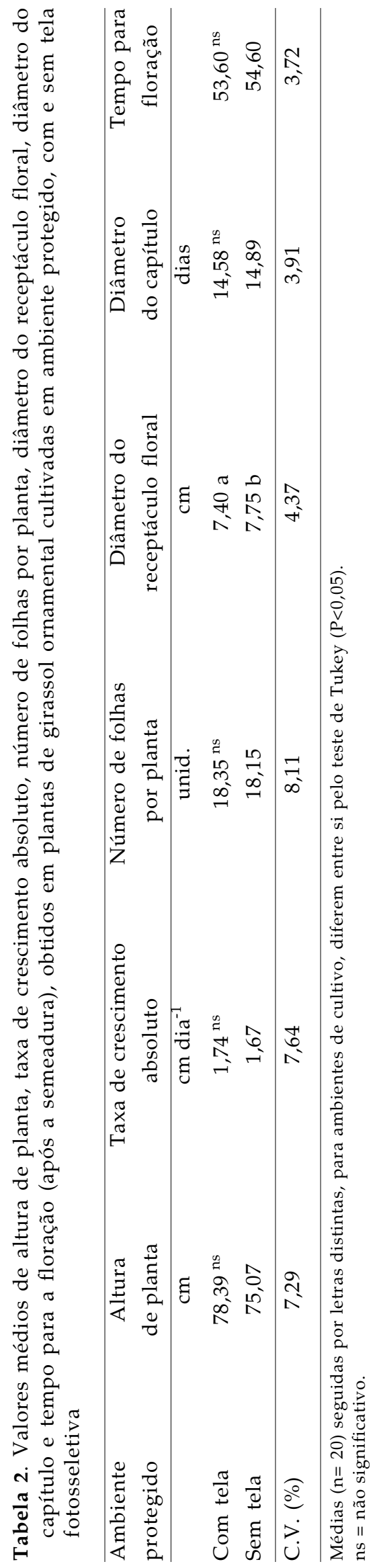

Bragantia, Campinas, v.68, n.3, p.681-687, 2009 
O cultivo protegido com tela fotosseletiva promoveu uma redução no diâmetro do receptáculo floral (ou disco) de 4,5\%, porém, não houve efeito significativo sobre diâmetro do capítulo floral (Tabela 2).

Não houve diferença no tempo necessário para floração ( $50 \%$ de capítulos formados), entre os ambientes estudados, cujas médias se situaram em torno dos 54 dias após a semeadura (Tabela 2).

O uso de doses crescentes de paclobutrazol determinou redução significativa na altura das plantas de girassol ornamental (Figura 1), como, também, observado por Almeida e Pereira (1996), Whipker e Dasoju (1998), Vernieri et al. (2003) e WANDERLEY et al. (2007) em outras cultivares de girassol. A variação na altura das plantas em função das doses do regulador de crescimento, após 44 dias do transplantio, foi expressa por uma regressão quadrática (Figura 2), a partir da qual a altura mínima foi estimada para dose próxima a $1,0 \mathrm{mg}$ de paclobutrazol por litro de substrato.

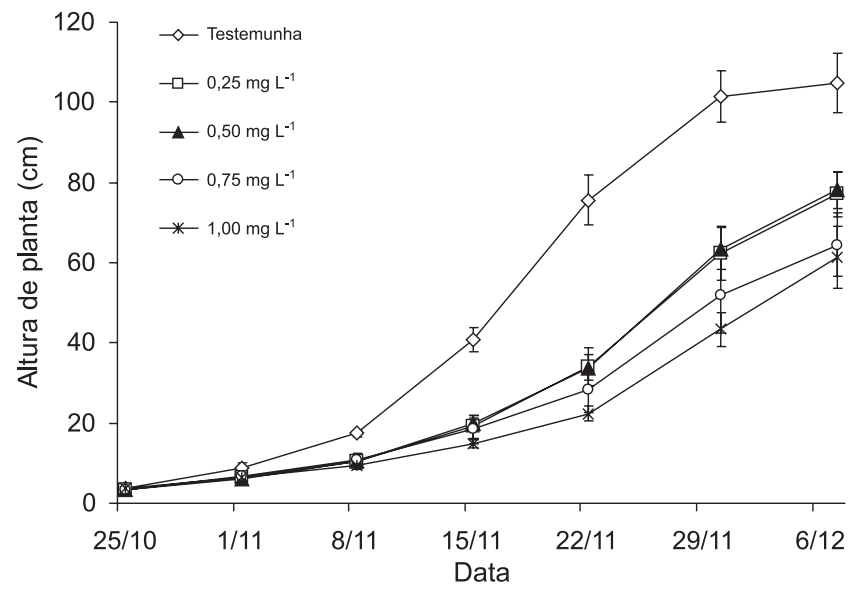

Figura 1. Crescimento de girassol ornamental em vaso em função de doses de paclobutrazol. As plantas foram desenvolvidas em ambiente protegido e cada símbolo representa o valor médio de oito repetições ( \pm desviopadrão).

O menor porte das plantas resultou de reduções significativas nas taxas de crescimento absoluto das plantas (de 2,30 para 1,34 $\mathrm{cm} \mathrm{dia}^{-1}$ ) devido ao incremento na concentração de paclobutrazol (de 0,0 para 1,0 $\mathrm{mg} \mathrm{L}^{-1}$ de substrato), segundo um ajuste quadrático (Figura 2). A redução na altura das plantas, com uso de paclobutrazol, pode ser explicada pela ação bloqueadora do regulador de crescimento sobre as reações de oxidação na passagem de caureno para ácido caurenóico, no caminho de síntese de substâncias giberelínicas (Almeida e Pereira, 1996; Fletcher et al., 2000).
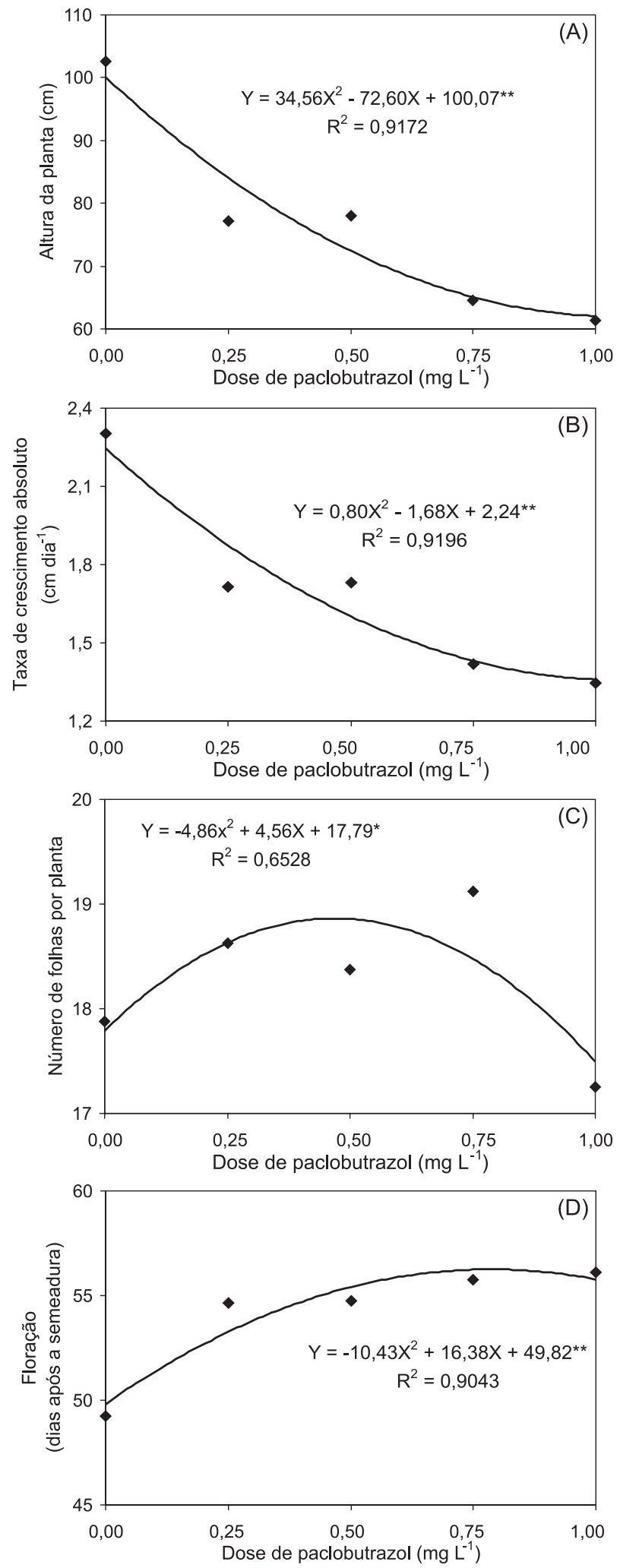

Figura 2. Variação na altura da planta (A), na taxa de crescimento absoluto (B), no número de folhas por planta (C) e no intervalo de tempo entre a semeadura e a floração (D), em função de doses de paclobutrazol, em girassol cV. Sunbright Supreme cultivado em ambiente protegido. * - significativo $(\mathrm{P}<0,05) ;{ }^{* *}$ - significativo $(\mathrm{P}<0,01)$. Cada símbolo representa o valor médio de oito repetições. 
O número de folhas por planta foi afetado pelo uso do regulador de crescimento, sendo os maiores valores obtidos com as doses intermediárias $(0,25 ; 0,50$ e $0,75 \mathrm{mg} \mathrm{L}^{-1}$ de substrato). Essa resposta seguiu um modelo quadrático (Figura 2), com ponto de máximo (18,86 folhas por planta) para a dose de $0,47 \mathrm{mg}$ de paclobutrazol por litro de substrato. Esses resultados divergem daqueles obtidos por Almeida e Pereira (1996), quando observaram que o paclobutrazol não altera o número de primórdios foliares, apesar de provocar atraso em seu desenvolvimento.

Embora a variação no número de folhas por planta em função das doses de paclobutrazol tenha sido significativa, é importante ressaltar que ela ocorreu dentro de limites sem importância comercial, ao contrário do porte das plantas que, realmente, influencia o aspecto visual dos vasos.

O diâmetro do receptáculo não variou significativamente em função das doses de paclobutrazol, situando-se entre 7,4 e 7,9 cm.

Da mesma forma, o de regulador de crescimento não produziu efeito significativo sobre o diâmetro do capítulo floral, que ficou entre 14,5 e 15,2 $\mathrm{cm}$ nesse estudo, distintamente do que foi obtido por WANDerley et al. (2007). Nossos resultados demonstraram que o uso de paclobutrazol reduziu o porte das plantas de girassol cv. Sunbright Supreme, tornando-as mais apropriadas para a comercialização em vaso sem, contudo, interferir negativamente no diâmetro da inflorescência.

Entretanto, o uso de paclobutrazol retardou a floração, resultado semelhante ao de WHIPKER e DASOJU (1998). Esse atraso variou com a concentração do regulador de crescimento, segundo uma regressão quadrática (Figura 2). O intervalo de tempo entre a semeadura e a floração situou-se em torno de 49 dias, nas plantas que não receberam o regulador de crescimento, enquanto o daquelas tratadas esteve ao redor de 56 dias. Logo, houve um atraso de aproximadamente uma semana, ou seja, um incremento de cerca de $14 \%$ no tempo necessário para a floração.

\section{CONCLUSÕES}

1. O uso de tela fotosseletiva azul $(30 \%$ de sombreamento) sob o filme plástico não diminui a altura das plantas de girassol cv. Sunbright Supreme, cujo porte, nessas condições, foi inadequado para comercialização em vasos.

2. O uso de paclobutrazol, aplicado no substrato nas doses de 0,75 e $1,0 \mathrm{mg} \mathrm{L}^{-1}$, reduz sensivelmente a altura das plantas de girassol ornamental, permitindo sua comercialização em vasos sem, contudo, alterar as demais características desejáveis, como o diâmetro do capítulo.

\section{AGRADECIMENTOS}

À FAPESP, pelo auxílio financeiro para realização do trabalho - processo $\mathrm{N}^{\circ}$ 2004/00069-1.

\section{REFERÊNCIAS}

ALMEIDA, J.A.S.; PEREIRA, M.F.D.A. Efeito de GA $_{3}$ e paclobutrazol no desenvolvimento vegetativo do girassol. Revista Brasileira de Fisiologia Vegetal, v.9, p.55-60, 1996.

BANZATTO, D.A., KRONKA, S.N. Experimentação Agrícola. 4 ed. Jaboticabal: FUNEP, 2006. 237p.

BENINCASA, M. M. P. Análise de crescimento de plantas (noções básicas). Jaboticabal: FUNEP, 1988. 42p.

BLISKA JUNIOR, A.; HONÓRIO, S.L. Características óticas de materiais de cobertura de viveiros e estufas. In: CONGRESSO BRASILEIRO DE ENGENHARIA AGRÍCOLA, 23., 1994, Campinas. Programas e Resumos... Campinas: UNICAMP, Jaboticabal: SBEA, 1994. p.284.

CASTILLA, N. Invernaderos de plástico: tecnología y manejo. Madri: Ediciones Mundi-Prensa, 2005. 461p.

CASTRO, C., CASTIGLIONI, V.B.R., BALLA, A., LEITE, R.M.V.B.C., KARAM, D., MELLO, H.C., GUEDES, L.C.A., FARIAS, J.R.B. A cultura do girassol. Londrina: EMBRAPACNPSo, 1997. 36p. (Circular Técnica 13)

CUQUEL, F.L., LEITE, C., DINIZ, G., ROSA, O.A.D. Produção de plantas de jardim em ambiente protegido com sombreamento por malhas que mudam o espectro solar. In: CONGRESSO BRASILEIRO DE FLORICULTURA E PLANTAS ORNAMENTAIS, 14, 2003, Lavras. Anais... Lavras: UFLA/ FAEPE, 2003. p.381.

FLETCHER, R.A.; GILLEY, A.; SANKHLA, N.; DAVIS, T. Triazoles as plant growth regulators and stress protectants. Horticultural reviews, v. 24, p. 55-138, 2000.

HANAN, J.J. Greenhouses: Advanced Technology for protected horticulture. Boca Raton: CRC Press, 1998. 684p.

JUNQUEIRA, A.H., PEETZ, M.S. Las exportaciones brasileñas de flores y plantas crecen más del 124\% entre 2001 y 2006. Horticultura Internacional, n. 56, p.76-79, 2007.

MANTALLANA, A., MONTERO, J.I. Invernaderos: diseño, construcción y climatización. 2ed. Madri: Ediciones MundiPrensa, 2001. 209p.

MARTINS, S.R., FERNANDES, H.S., ASSIS, F.N., MENDEZ, M.E.G. Caracterização climática e manejo de ambientes protegidos: a experiência brasileira. Informe Agropecuário, v.20, n.200/201, p.15-23, 1999. 
MONTERO, J.I.; ANTÓN, A. Greenhouse cooling during warm periods. Acta Horticulturae, p.49-61 1994.

NEVES, M.B. Desenvolvimento de plantas de girassol ornamental (Helianthus annuus L.) em vasos em dois substratos, com solução nutritiva e em solo. Ilha Solteira, 2003. 63p. Dissertação (Mestrado em Sistemas de Produção) Faculdade de Engenharia de Ilha Solteira, Universidade Estadual Paulista.

PAPADAKIS, G., BRIASSOULIS, D., SCARASCIA MUGNOZZA, G., VOX, G., FEUILLOLEY, P.; STOFFERS, J. A. Radiometric and thermal properties of, and testing methods for, greenhouse covering materials. Journal of Agricultural Engineering Research, v.77, p.7-38, 2000.

POLYSACK. Disponível em: http://www.polysack.com/ index.php?page_id=214. Acesso em 9/5/2008.

RAJAPAKSE, N.C., YOUNG, R.E., MCMAHON, M.J., OI, R. Plant height control by photoselective filters: current status and future prospects. HortTechnology, v.9, p.618-624, 1999.

RAJAPAKSE, N.C.; KELLY, J.W. Regulation of chrysanthemun growth by spectral filters. Journal of American Society for Horticultural Science, v.117, p.481-485, 1992.

SERRANO CERMEÑO, Z. Construcción de invernaderos. Madri: Ediciones Mundi-Prensa, 1994. 445p.

VERNIERI, P., INCROCCI, G., TOGNONI, F., SERRA, G. Effect of cultivar, timing, growth retardants, potting type on potted sunflowers production. In: INTERNATIONAL SYMPOSIUM ON PROTECTED CULTIVATION IN MILD WINTER CLIMATE: PRODUCT AND PROCESS INNOVATION, 6., 2002, Ragusa - Itália. Acta Horticulturae, v. 614, p.313-318, 2003.

WANDERLEY, C.S., REZENDE, R., ANDRADE, C.A.B. Efeito de paclobutrazol como regulador de crescimento e produção de flores de girassol em cultivo hidropônico. Ciência e Agrotecnologia, v.31, p.1672-1678, 2007.

WILSON, S.B.; RAJAPAKSE, N.C. Growth control of lisianthus by photoselective plastic films. HortTechnology, v.11, p.581584, 2001.

WHIPKER, B.E.; DASOJU, S. Potted sunflower growth and flowering responses to foliar applications of diaminozide, paclobutrazol e uniconazole. HortTechnology, v.8, p.8688, 1998.

ZIMMERMANN, F.J.P. Estatística aplicada à pesquisa agrícola. Santo Antônio de Goiás: Embrapa Arroz e Feijão, 2004. 402 p. 